\title{
Further Studies on the Cytology of Central and East Himalayan Grasses
}

\author{
P. N. Mehra and M. L. Sharma \\ Department of Botany, Panjab University, Chandigarh, India
}

Received February 21, 1976

This is in continuation of our previous work on the cytoloty of Central and East Himalayan grasses, under which data on the cytology of 173 taxa belonging to 141 species of grasses have already been presented ((Mehra and Sharma 1975 a-f). In the present paper, the results of cytological studies in 20 more taxa belonging to 13 species from the hills of Darjeeling (E. Himalayas) are being reported.

\section{Material and methods}

The material for meiotic studies was procured from natural populations growing in and around Darjeeling. The methods employed for meiotic studies were the same as discussed in our earlier papers (see Mehra and Sharma 1975). For somatic chromosome studies of bamboos, the rhizomes were wrapped in wet moss material and placed in polythene bags for 7-8 days for obtaining actively growing root-tips. These were pretreated with $0.004 \mathrm{M}, 8$-hydroxyquinoline for 4-5 hours at room temperature $\left(15^{\circ} \mathrm{C}-20^{\circ} \mathrm{C}\right)$, fixed in $1: 3$ acetic-alcohol for about 1 hour and kept overnight in $2 \%$ aceto-lacmoid. The hydrolysis was carried out in $\mathrm{N} . \mathrm{HCl}$ for $10-15$ minutes and the squashing accomplished in $2 \%$ aceto-lacmoid. The slides were passed through acetic acid-n-butyl alcohol grades and mounted in Euparal. The voucher specimens have been deposited in the Herbarium of the Botany Department, Panjab University Chandigarh. Pollen fertility refers to morphologically normal pollen which stained with carmine. All the photomicrographs are at a uniform magnification of $\times 1500$.

\section{Results and discussion}

Table 1 summarises the results of cytological observations on 20 taxa belonging to 13 species. In the succeeding pages, only the interesting features in some of the species are given.

Agrostis stolonifera Linn.

This grass forms an important part of the alpine pastures in the hills of India and is a welcome fodder.

The populations growing on the border of Senchal Lake in Darjeeling revealed a haploid set of 14 chromosomes along with 3B-chromosomes of comparatively small size. The 3 B's were associated to form a trivalent in some of the PMC's (Fig. 3) whereas in others, two of the B's formed a bivalent and the third one could be seen as 


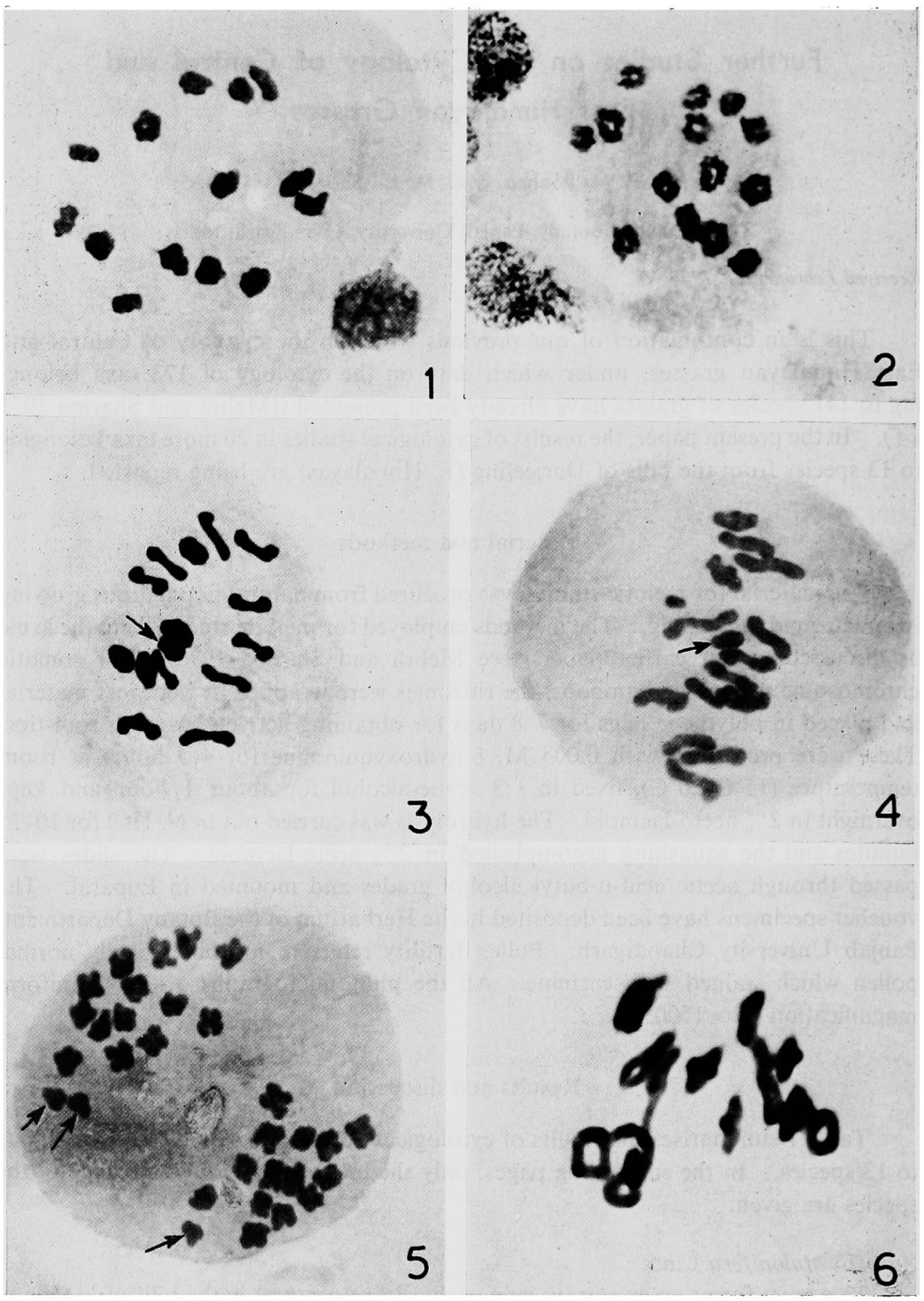

Figs. 1-6. 1, Agrostis micrantha Steud., diakinesis, $\mathrm{n}=14,2$, A. myriantha Hook. f. diakinesis, $\mathrm{n}=14$. 3-5, A. stolonifera Linn. 3, $\mathrm{M}_{1}, \mathrm{n}=14+3 \mathrm{~B}$ 's forming a trivalent (arrow). $4, \mathrm{n}=14+3 \mathrm{~B}$. The 2B's forming a bivalent (arrow) and the third univalent B. 5, $\mathrm{A}_{1}$, showing 16 chromosomes $(14+2 B)$ at one pole and 15 chromosomes $(14+1 B)$ at the other (B-chromosomes are at arrows). 6 , Bromus japonicus Thunb. var. japonicus, $\mathrm{M}_{1}$, showing secondary associations among the bivalents and a configuration of 4 bivalents. 


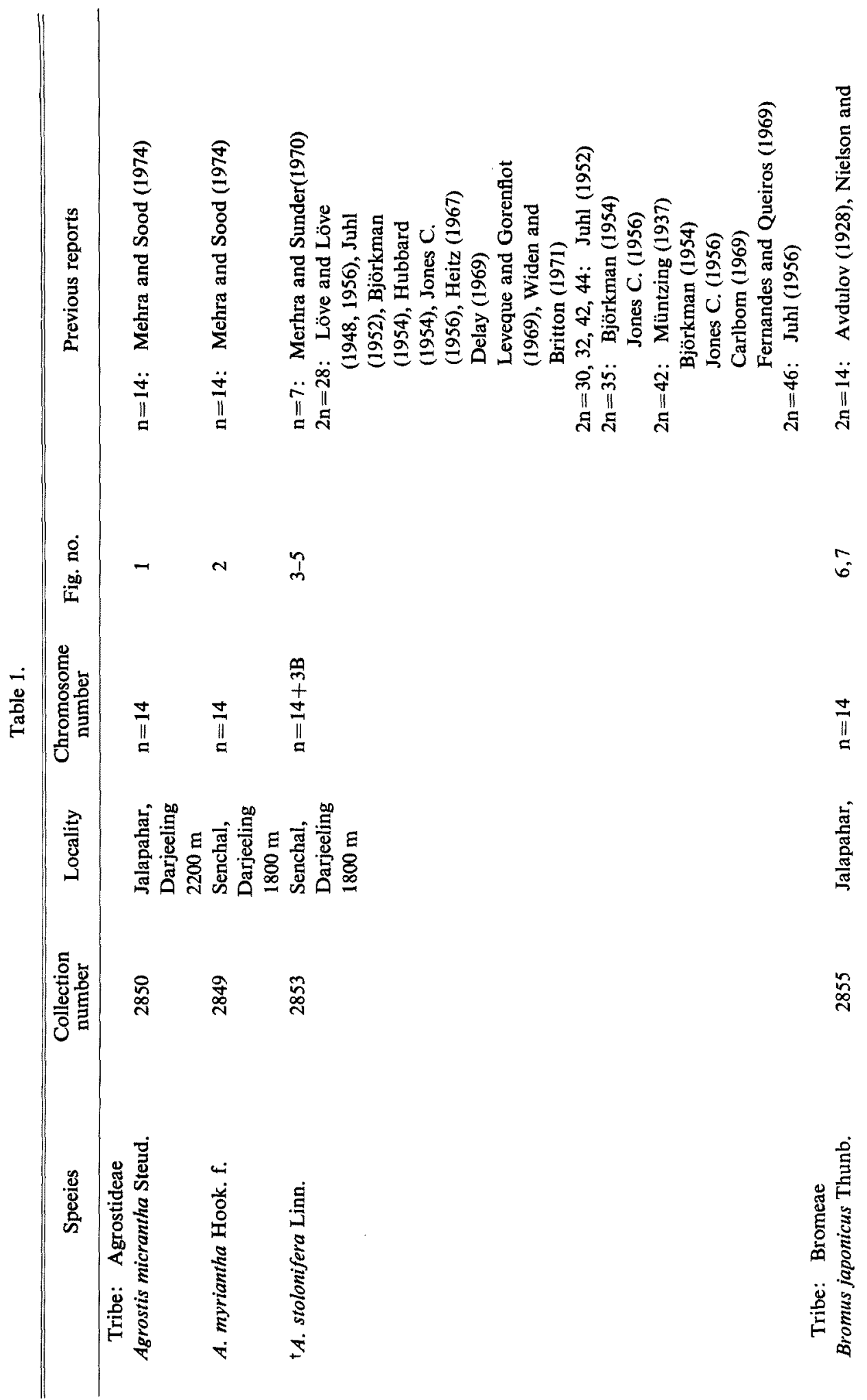




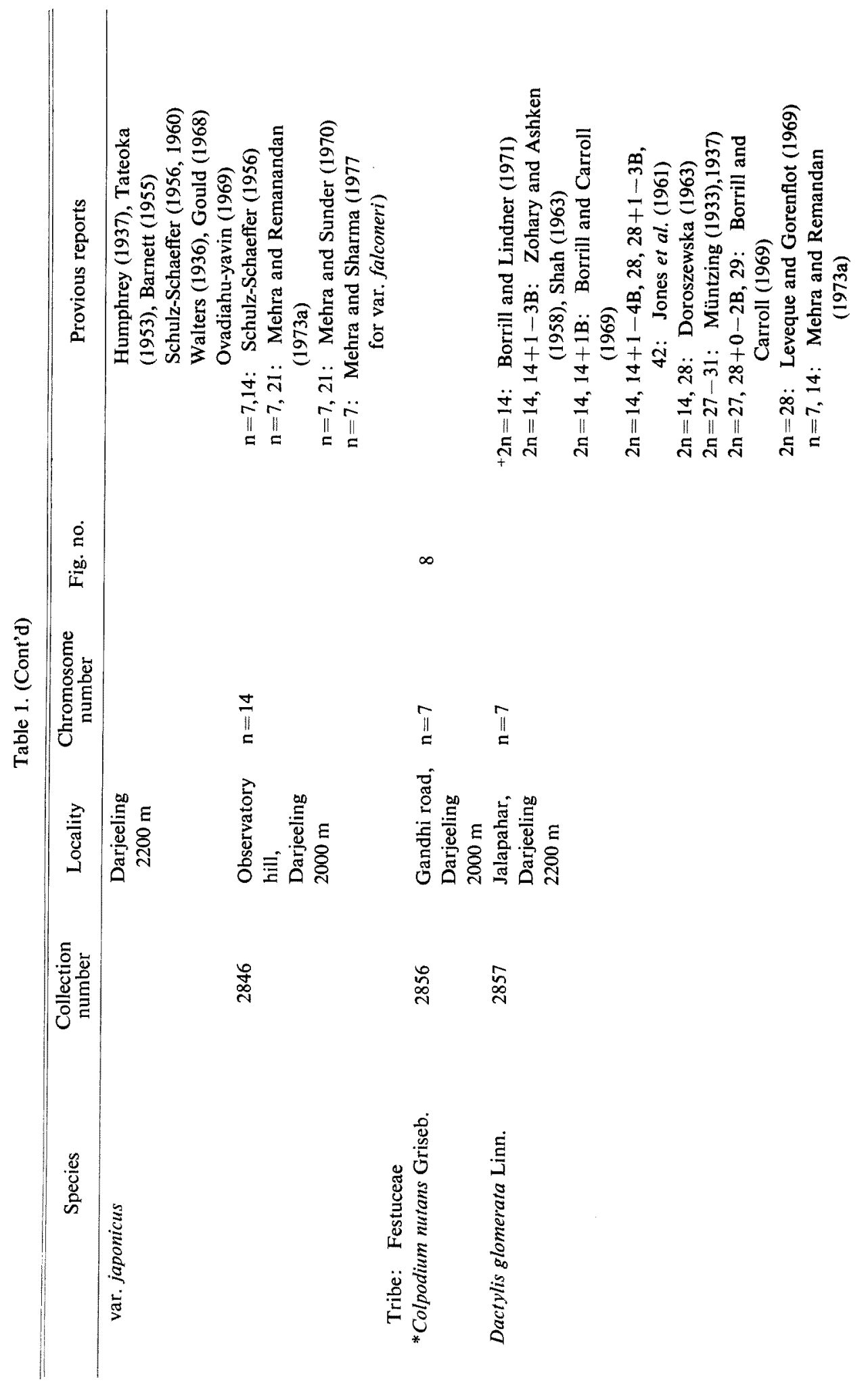



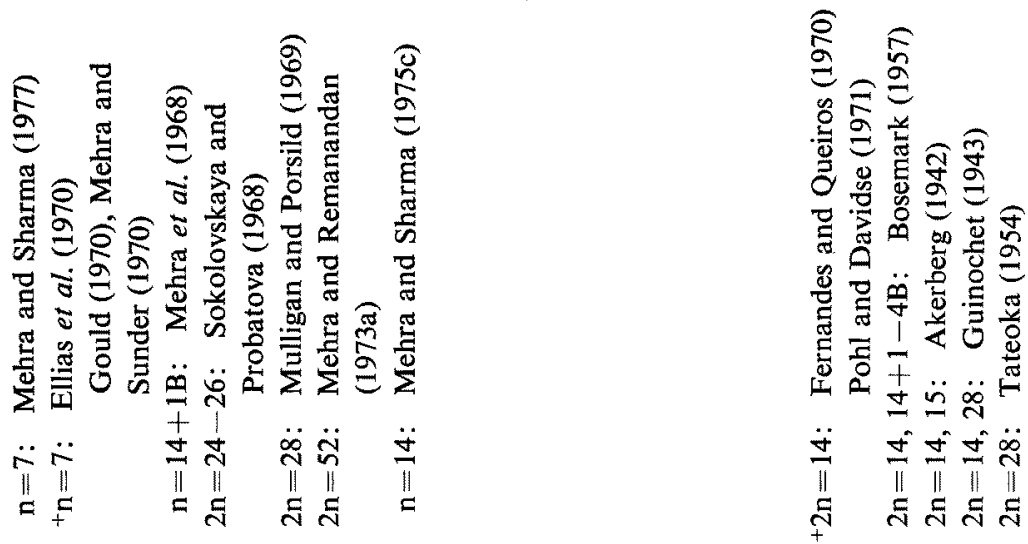

a

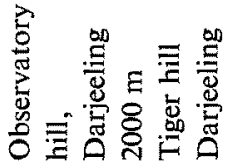

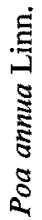

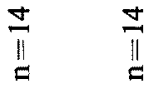

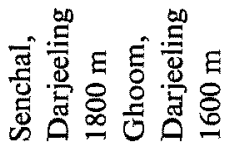

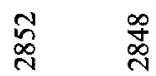

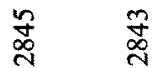

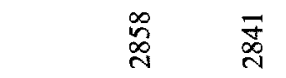

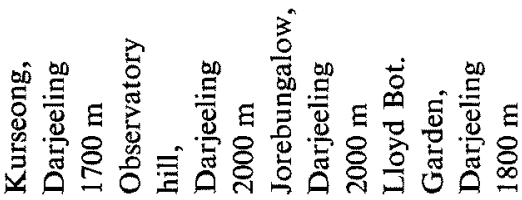

$\underset{\Xi}{ \pm} \quad \underset{\Xi}{ \pm}$

$\stackrel{\nabla}{I}$

II

$\pi \quad \pi$

$\underset{\sim}{\mathbb{Z}}$
莳 


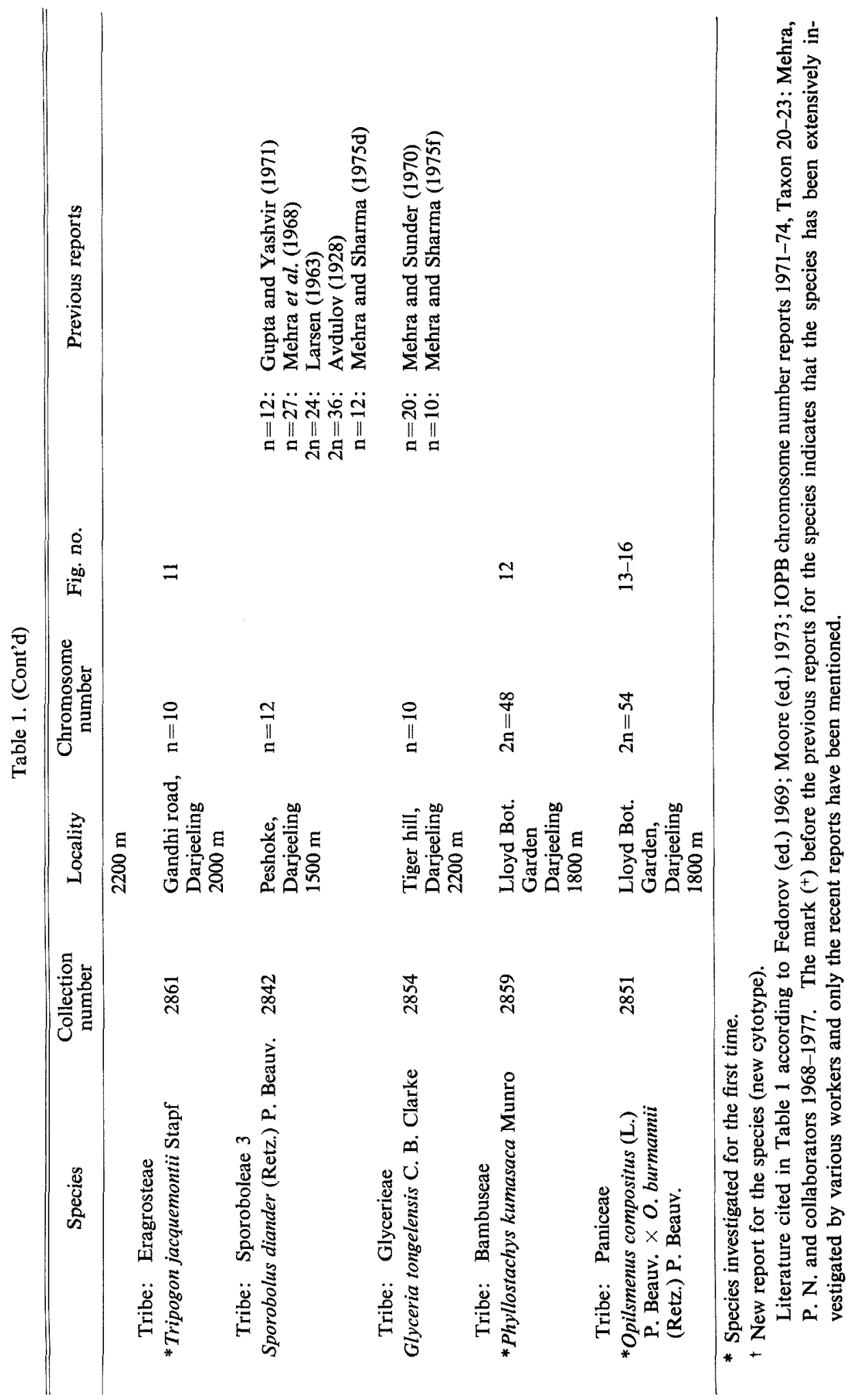


a univalent (Fig. 4). At anaphase I, the B's were distributed at the two poles in the ratio of $2: 1$ so that the PMC's at this stage showed 16 chromosomes $(14+2 B)$ at one pole and 15 chromosomes $(14+1 \mathrm{~B})$ at the other (Fig. 5). Meiosis was quite normal as evidenced by nearly $100 \%$ pollen fertility.

\section{Bromus japonicus Thunb. var. japonicus}

It is one of the most common among the good fodder grasses in the N.W. Himalayas and occurs usually on abandoned cultivation.

Meiotic studies revealed the present taxon to be tetraploid with $n=14$. The PMC's at diakinesis and $\mathrm{M}_{1}$ showed nonhomologous bivalent associations with a tendency among some of the bivalents to form multivalent configurations (Fig. 6). Thus, an exact chromosome count was made difficult at these stages. At $\mathrm{A}_{1}$ too, a similar tendency was noticed but here, in some of the PMC's, 14 chromosomes could be counted at each pole. About $92 \%$ pollen fertility was recorded.

\section{Colpodium nutans Griseb}

This grass grows at very high altitudes of North-West India and is not much valued as a fodder.

The present collections were made from populations of only $4-5$ individuals growing on the road-side near B. T. College, Darjeeling and was not observed to grow in any other locality. This species, which has been investigated for the first time, turned out to be diploid with $n=7$ (Fig. 8). A quadrivalent was invariably noticed in the PMC's at diakinesis and metaphase I. Anaphase I and further stages of meoisis were, however, normal and about $96 \%$ pollen were fertile.

\section{Poa trivialis Linn.}

This is a very good fodder grass which can also be made into hay.

Collections for meiotic studies were made from various localities of Darjeeling and nearby suburbs. In each case, a meiotic count of $n=7$ was observed (Fig. 9). The course of meiosis was normal except in the individuals from Tiger hill which showed nonhomologous bivalent associations at diakinesis and metaphase I (Fig. 10). Anaphase I was normal with 7:7 distribution of chromosomes. Pollen fertility was about $96 \%$.

\section{Phyllostachys kumasaca Munro}

This is a dwarf bamboo, upto 1 metre tall, and is cultivated in the Lloyd Botanical Gardens, Darjeeling.

The root tip preparations revealed a diploid chromosome number $2 n=48$ (Fig. 12). The karyotype could not be analysed due to very small size of the chromosomes. The genus Phyllostachys seems to be based on $\mathrm{x}=6$ as suggested by us earlier (Mehra and Sharma 1975e). The lowest haploid number, $n=12$, in bamboos is reported in this genus in P. makinoi by Hsu (1967), whereas all the other reports are of higher ploids.

Oplismenus compositus (L.) P. Beauv. $\times$ O. burmannii (Retz.) P. Beauv.

This grass collected from the Lloyd Botanical Gardens was found to form a 
turf under the shade of trees and resembled $O$. burmanii in appearance. However, on close examination of the inflorescence characters, it was found to match $O$. compositus. The inflorescence is a panicle of racemes arranged alternately on the axis

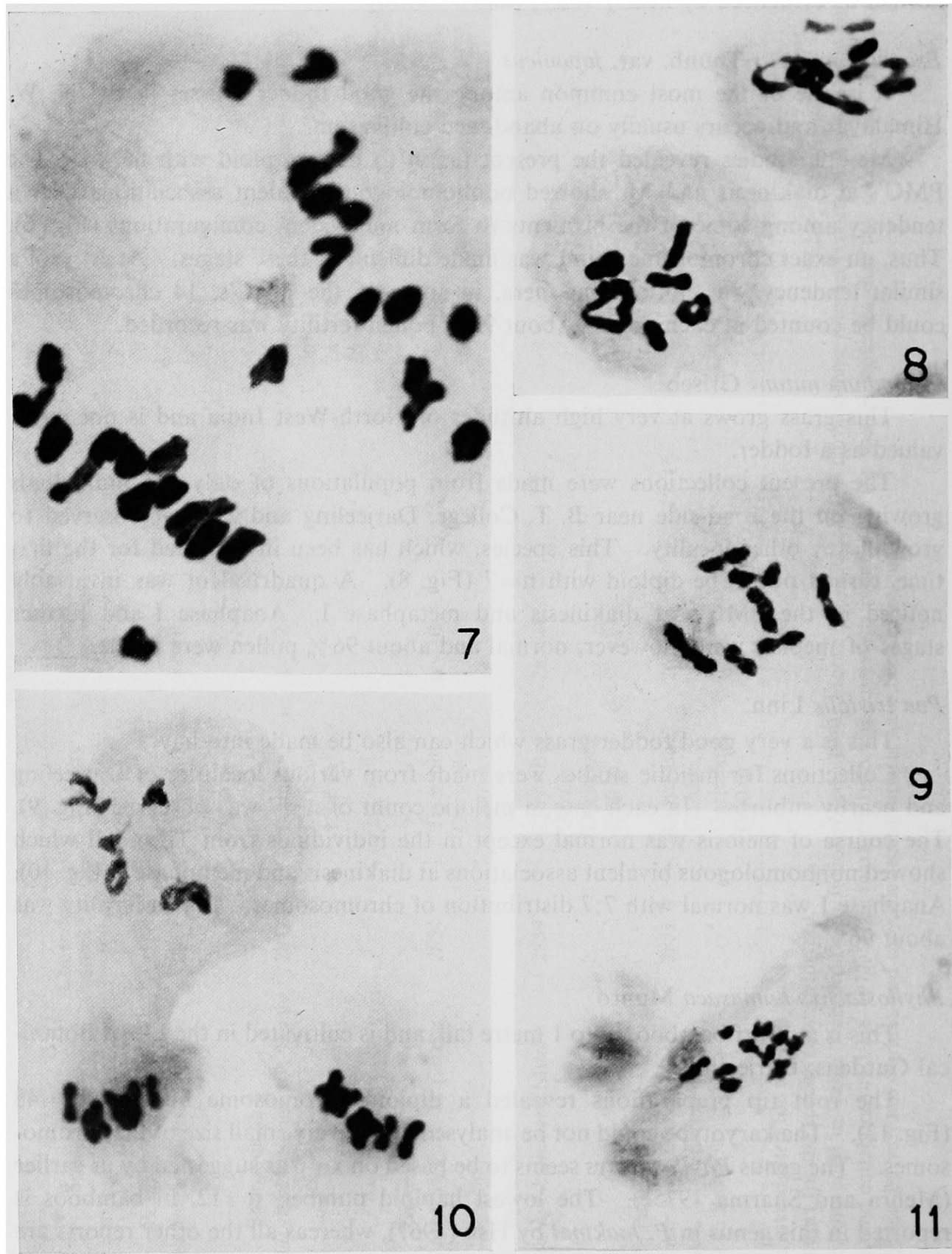

Figs. 7-11. 7, Bromus japonicus Thunb. var. japonicus, $\mathbf{A}_{1}$ showing 14 chromosomes at each pole. 8, Colpodium nutans Griseb, diakinesis, $\mathrm{n}=7$ (note the quadrivalent). 9-10, Poa trivialis Linn. (Tiger hill population), diakinesis and $\mathbf{M}_{1}$ showing secondary associations among the bivalents, $\mathrm{n}=7$. 11, Tripogon jacquemontii Stapf, $\mathrm{M}_{1}, \mathrm{n}=10$. 
and the awns of the spikelets are reddish, and stiff. These are the characters of $O$. compositus. But the habit of growth, general appearance, hairiness of leaves and spikelets and the barbellate awns are like $O$. burmannii. The plant size is much smaller than either of them.

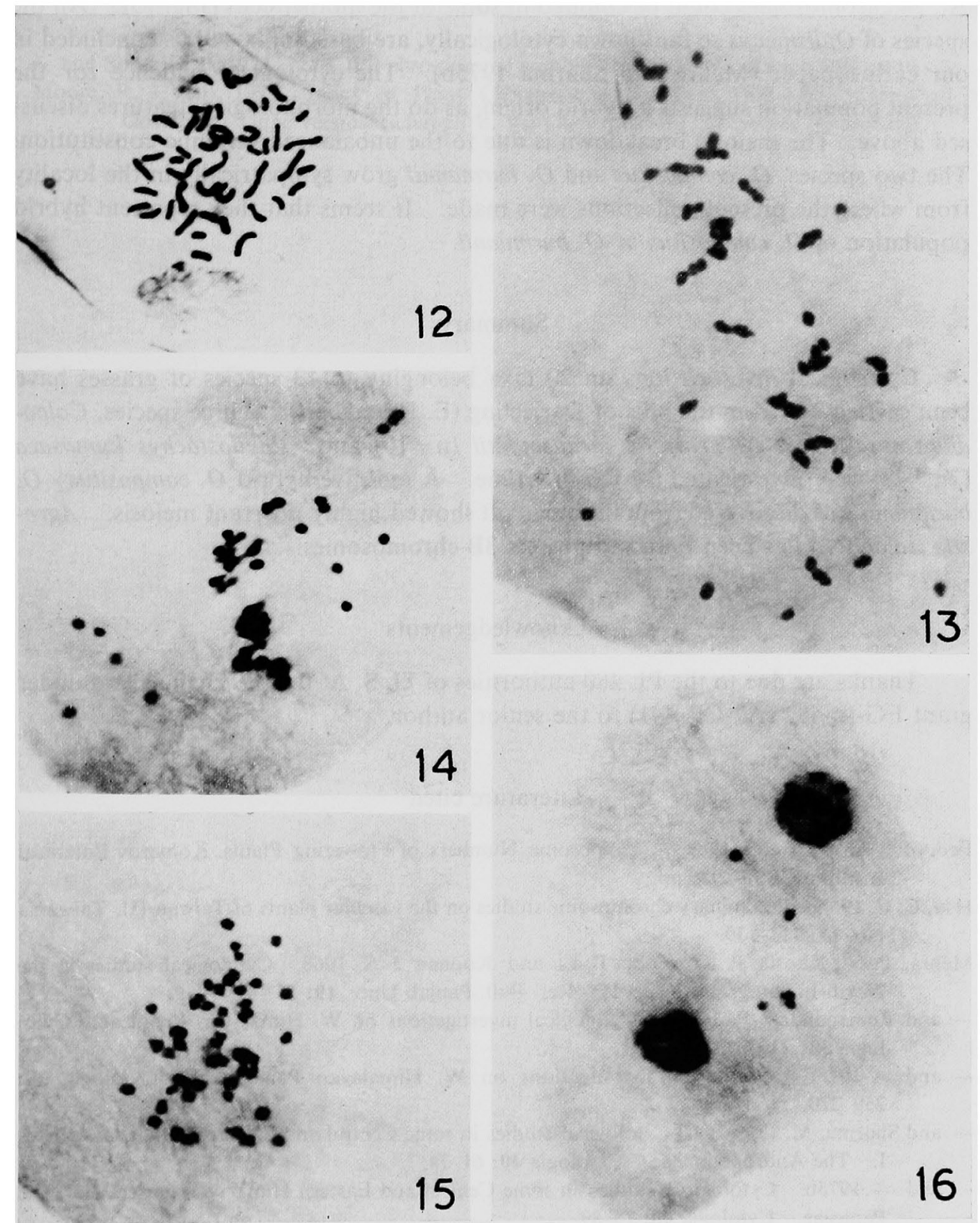

Figs. 12-16. 12, Phyllostachys kumasaca Munro, root-tip preparation showing $2 \mathrm{n}=48$ chromosomes. 13-16, Oplismenus compositus $\times O$. burmannii, $2 \mathrm{n}=54,13, \mathrm{M}_{1}$ showing univalents, bivalents and trivalents. $14, \mathrm{M}_{1}$ showing noncongression of univalents at the metaphase plate. 15 , mixed $A_{1}, 2 n=54$. 16 , late $A_{1}$ showing lagging chromosomes. 
Meiotic studies revealed an equally interesting situation. Meiosis was highly disturbed resulting in the production of $70 \%$ sterile pollen. The following were the chief aberrations noticed: i) nonhomologous bivalent associations, ii) loose pairing of chromosomes at diakinesis, iii) nonorientation of univalents, bivalents and trivalents at $M_{1}$ and lagging of chromosomes at $A_{1}$ (Figs. 13-16). At mixed $A_{1}, 54$ chromosomes could be counted in some of the mother cells (Fig. 15). All the species of Oplismenus so far known cytologically, are based on $\mathrm{x}=9$, as concluded in our earlier paper (Mehra and Sharma 1975b). The cytological evidence for the present population suggests a hybrid origin, as do the morphological features discussed above. The meiotic breakdown is due to the unbalanced genomic constitution. The two species, $O$. compositus and $O$. burmannii grow sympatrically in the locality from where the present collections were made. It seems that they represent hybrid population of $O$. compositus $\times O$. burmannii.

\section{Summary}

Cytological investigations on 20 taxa belonging to 13 species of grasses have been carried out from the hills of Darjeeling (E. Himalayas). Three species, Colpodium nutans $(\mathrm{n}=7)$, Tripogon jacquemontii $(\mathrm{n}=10)$ and Phyllostachys kumasaca $(2 \mathrm{n}=48)$ were investigated for the first time. A putative hybrid $O$. compositus $\times O$. burmannii was discovered from the area. It showed highly aberrant meiosis. Agrostis stolonifera has been found to possess 3B-chromosomes.

\section{Acknowledgements}

Thanks are due to the PL 480 authorities of U. S. A. for the financial aid under grant FG-In-482 (A7-CR-441) to the senior author.

\section{Literature cited}

Fedorov, An. A. (ed.) 1969. Chromosome Numbers of Flowering Plants. Komarov Botanical Institute USSR, $926 \mathrm{pp}$.

Hsu, C. C. 1967. Preliminary chromosome studies on the vascular plants of Taiwan (I). Taiwania No. 13: 117-130.

Mehra, P. N., Khosla, P. K., Kohli, B. L. and Koonar, J. S. 1968. Cytological studies in the North-Indian grasses (Part I), Res. Bull. Panjab Univ. 19: 157-230.

- and Remanandan, P. 1973a. Cytological investigations on W. Himalayan Pooideae. Cytologia 38: 237-258.

- and - 1973b. Cytological investigations on W. Himalayan Panicoideae. Cytologia 38: 259-270.

- and Sharma, M. L. 1975a. Cytological studies in some Central and Eastern Himalayan grasses

I. The Andropogoneae. Cytologia 40: 61-74.

- and - 1975b. Cytological studies in some Central and Eastern Hinalayan grasses II. The

Paniceae. Cytologia 40: 75-89.

- and - 1975c. Cytological studies in some Central and Eastern Himalayan grasses III. The Agrostideae, Aveneae, Brachypodieae, Bromeae, Festuceae, Phalarideae, and Triticeae. Cytologia 40: 441-452.

- and - 1975d. Cytological studies in some Central and Eastern Himalayan grasses IV. The 
Arundinelleae, Eragrosteae, Isachneae, Chlorideae, Sporoboleae, Meliceae, Stipeae, Arundineae and Garnotieae. Cytologia 40: 453-462.

- and - 1975e. Cytological studies in some Central and Eastern Himalayan grasses V. The Bambuseae. Cytologia 40: 463-467.

- and - 1975f. In IOPB chromosome number reports XLIX. Taxon 24 (4): 501-516.

— and - 1977. Cytological studies on some grasses of Kashmir. Cytologia 42: 111-123.

- and Sunder, Shyam 1970. Cytological studies in the North-Indian grasses (Part II). Res. Bull. Panjab Univ. 20: 503-539.

- and Sood, O. P. 1974. In IOPB chromosome number reports XLV. Taxon 23(4): 619-624.

Moore, R. J. (ed). 1973. Index to Plant Chromosome Numbers 1967-1971. Published by Oosthoek's Uitge versmaatschappij B. V., Domstraat 5-13, Utrecht, Netherlands. 